\title{
ddPCR allows 16S rRNA gene amplicon sequencing of very small DNA amounts from low-biomass samples
}

\author{
Isabel Abellan-Schneyder, Andrea Janina Schusser and Klaus Neuhaus* (0)
}

\begin{abstract}
Background: One limiting factor of short amplicon 165 rRNA gene sequencing approaches is the use of low DNA amounts in the amplicon generation step. Especially for low-biomass samples, insufficient or even commonly undetectable DNA amounts can limit or prohibit further analysis in standard protocols.

Results: Using a newly established protocol, very low DNA input amounts were found sufficient for reliable detection of bacteria using $16 \mathrm{~S}$ rRNA gene sequencing compared to standard protocols. The improved protocol includes an optimized amplification strategy by using a digital droplet PCR. We demonstrate how PCR products are generated even when using very low concentrated DNA, unable to be detected by using a Qubit. Importantly, the use of different $16 \mathrm{~S}$ rRNA gene primers had a greater effect on the resulting taxonomical profiles compared to using high or very low initial DNA amounts.

Conclusion: Our improved protocol takes advantage of ddPCR and allows faithful amplification of very low amounts of template. With this, samples of low bacterial biomass become comparable to those with high amounts of bacteria, since the first and most biasing steps are the same. Besides, it is imperative to state DNA concentrations and volumes used and to include negative controls indicating possible shifts in taxonomical profiles. Despite this, results produced by using different primer pairs cannot be easily compared.
\end{abstract}

Keywords: ddPCR, Very small DNA amounts, Low-biomass samples, $16 \mathrm{~S}$ rRNA gene sequencing

\section{Background}

In 1985, the $16 \mathrm{~S}$ rRNA gene was described for the first time as a molecular tool for identifying microbes that were previously shown to be unculturable [1]. This ubiquitous bacterial gene possesses special features containing conserved regions that enable primer binding and thus amplification, as well as hypervariable regions allowing phylogenetic differentiation. Thus, sequencing of the 16S rRNA gene still is the current method of choice to analyze taxonomical profiles of mixed bacterial

\footnotetext{
*Correspondence: neuhaus@tum.de

Core Facility Microbiome, ZIEL - Institute for Food \& Health, Technische Universität München, Freising, Germany
}

communities [2, 3]. An often applied, easy, time- and cost-efficient method nowadays is short-amplicon sequencing using second-generation sequencers such as the Illumina MiSeq. Several factors affecting 16S rRNA gene sequencing results have been widely studied. Some of those are sampling and sample storage [4-7], the use of different variable regions or primers [8-12], sequence processing including the use of different denoising approaches, reference databases, and downstream analysis pipelines [13-18].

In addition to the above, it was previously shown that the extracted DNA can impact $16 \mathrm{~S}$ rRNA analysis in two ways. Firstly, the use of different extraction methods or protocols influences the composition of a given sample [19-23]. More precisely, easy to lyse Gram-negative 
bacteria are favored by several extraction methods compared to hard to lyse Gram-positive bacteria [24-26]. Secondly, the DNA concentrations used for amplicon generation can influence the resulting taxonomical profiles [27]. This becomes even more critical when low biomass samples are analyzed, because contaminations (including eukaryotic non-target DNA) of those samples would more likely affect the resulting taxonomical profiles and, thus, could lead to distorted study results [28-30]. Lowering input amounts for 16S rRNA gene sequencing approaches are of particular interest for researchers investigating, e.g., the lower respiratory tract, preterm child microbiomes, stool samples of patients treated with antibiotics, milk samples, or any other sample type which is considered to be of low bacterial biomass [31-35]. Only very few studies tried to find minimum input amounts that are needed to produce reliable results. Brandt and Albertsen [36] defined a detection limit for bacteria in drinking water. They showed that if the bacterial input is $10^{1}$ cells $/ \mathrm{ml}$ or smaller, several contaminating Operational Taxonomic Units (OTUs) appeared, and thus, sample outcomes could not be counted as reliable data. Multinu, et al. [27] reported that a minimum concentration of $40 \mathrm{pg} / \mu \mathrm{l}$ and an ideal concentration of $>200 \mathrm{pg} / \mu \mathrm{l}$ produce reliable $16 \mathrm{~S}$ rRNA gene profiles of human stool samples. Velásquez-Mejía, et al. [37] showed that they needed at least $2 \mathrm{mg}$ of fecal sample to extract sufficient DNA for 16S rRNA gene sequencing and the lowest successful amount of DNA used was $500 \mathrm{pg} / \mu \mathrm{l}$ in their study.

Here, we wanted to assess whether we could decrease the minimum input amount of DNA needed for reliable 16S rRNA gene sequencing of human stool and other samples even further. As a comparison, input amounts of 1-100 ng of DNA are commonly used for PCRs designated to perform later $16 \mathrm{~S}$ rRNA gene sequencing. Illumina suggests using $12.5 \mathrm{ng}$ total DNA input for a first step PCR (Illumina Inc., 16S Metagenomic Sequencing Library Preparation, Part \#15044223 Rev.B). In our lab, we use 12 ng total DNA in our standard 16S rRNA gene sequencing approaches [38]. To enable the use of lower input amounts, we implemented a digital droplet PCR (ddPCR) approach followed by standard short amplicon 16S rRNA gene sequencing.

Common PCRs take place in larger reaction volumes between about 20 to $50 \mu \mathrm{l}$. An advancement is the ddPCR, which splits the larger volume into about 20,000 droplets, in which independent reactions occur within each droplet. Dividing the PCR volume into thousands of droplets has certain advantages: ddPCR was shown to be less sensitive to inhibitors [39] and was able to allow for selective and reproducible detection of rare alleles and the absolute quantification of targeted gene copy numbers [40]. Other benefits of ddPCR protocols are a reduced PCR bias by avoiding preference in the amplification of specific products over others by dividing the reaction mixture into small droplets, a simplified quantification compared to qPCR, and reduced consumable costs, as reaction volumes are small [41]. Gobert, et al. [42] showed a quantification method for low amounts of Lactobacilli in fecal samples using a ddPCR approach. There, quantification was possible even though only low numbers of the target strains were present within high background. Wouters, et al. [43] stated that by using a ddPCR protocol, they could detect very low amounts of a pathogen's DNA in whole blood samples in as short as 4 h. In 2015, Boers, et al. [44] described a method were they performed micelle PCRs, a very similar concept to ddPCR, coupled with sequencing of the re-extracted $16 \mathrm{~S}$ rRNA genes using a 454 GS Junior Sequencer platform (Roche). They showed that using the micelle PCR instead of a standard 16S PCR protocol reduces chimera formation in $16 \mathrm{~S}$ rRNA profiling. Other studies investigating the coupling of microdroplet-based PCRs together with next generation sequencing strategies have been described previously [45-47], but for different purposes. In these studies, genes of interest, e.g., genes involved with congenital muscular dystrophies [45] or genes associated with diabetes and obesity [47] are screened by using a microdroplet-based PCR for enrichment next-generation sequencing reads for analysis. In the presented study, applicability and limits of ddPCR were tested in order to reliably obtain results for $16 \mathrm{~S}$ rRNA gene sequencing with very low input amounts of initial DNA.

\section{Results}

\section{Study overview}

The influence of the initial input amount of DNA was studied in detail. Towards this end, a general, published workflow for $16 \mathrm{~S}$ rRNA gene amplicon sequencing was followed for the first part of the library preparation [38]. Subsequently, after purifying the amplicons after the 2nd-step PCR (i.e., barcoding), a ddPCR step was added allowing processing and later sequencing of initially very low DNA input amounts (Fig. 1).

First, to establish the new protocol, two different tests were performed. We prepared and sequenced, firstly, standard PCR products generated by using 12 ng DNA input (standard amount for $16 \mathrm{~S}$ rRNA gene sequencing approaches in our laboratory). The very same samples were processed after the 2nd-step PCR by a further ddPCR step. Towards this end, samples were diluted, ddPCR performed and sequenced. By comparing the resulting sequences of both procedures, we evaluated whether the ddPCR step introduces bias. 


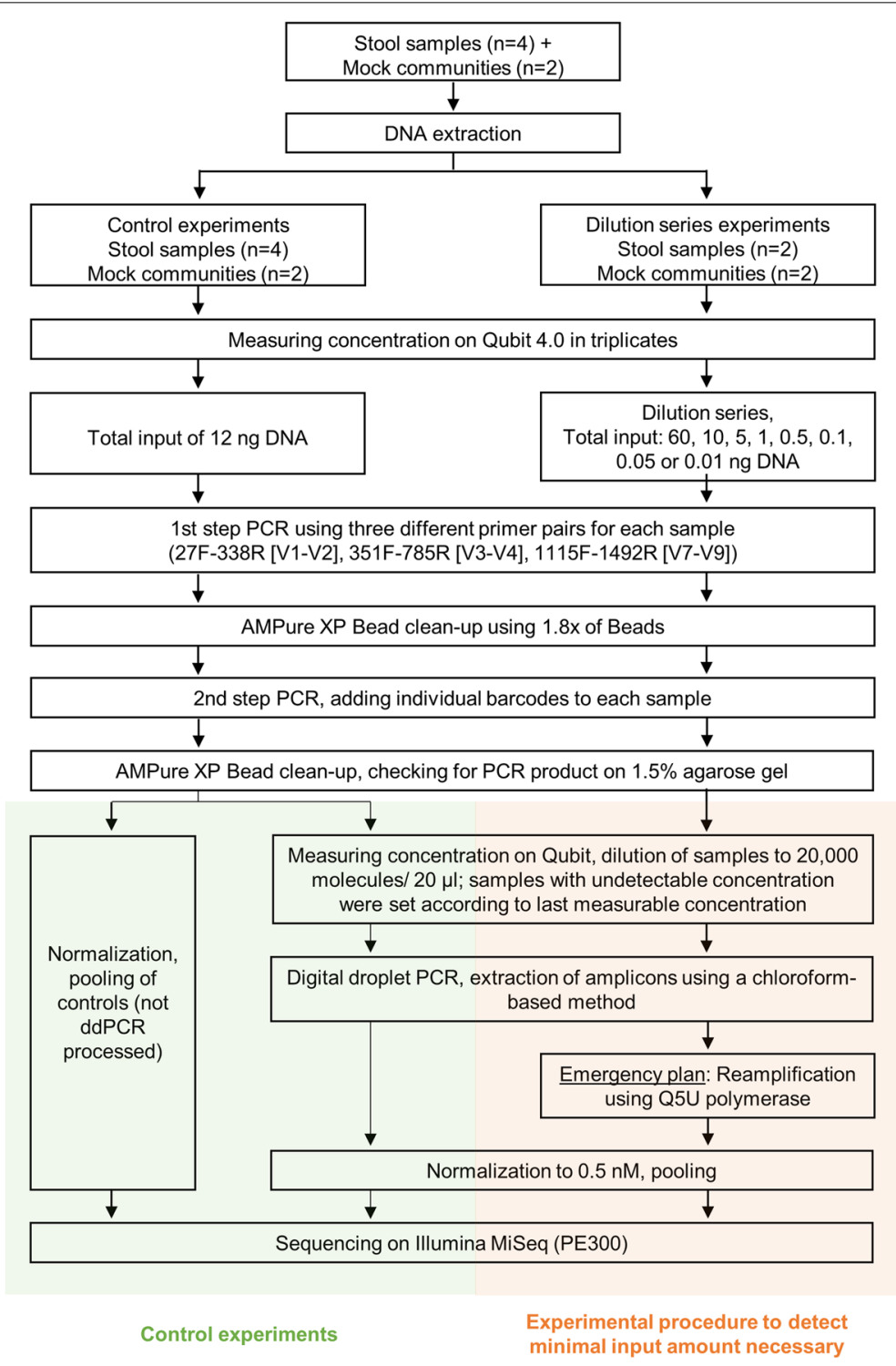

Fig. 1 Overview of experimental procedure of this study. Experiments are divided into two parts. Left, control experiments (shaded green) were used for checking if the additional ddPCR step did not introduce bias in the resulting taxonomical profiles. Right, experimental procedures (shaded red) were described to detect the minimum input amount of DNA input necessary to produce reliable $16 \mathrm{~S}$ rRNA gene sequencing results

Secondly, we performed dilution series and used decreasing amounts of initial DNA input $(60,10,5,1$, $0.5,0.1,0.05$, and $0.01 \mathrm{ng}$ total input) in the 1st-step PCR. Subsequently, a standard 2nd-step PCR was performed, the resulting amplicon samples were diluted, processed by ddPCR, and sequenced. Using this approach, we evaluated whether we were able to produce reliable results even when DNA input amounts below $500 \mathrm{pg}$ were used. Taken together, we compared resulting taxonomical profiles and whether they are independent of the DNA input amount used in 1st-step PCR or independent of an additional ddPCR (Fig. 1).
In brief, DNA of stool samples were extracted, concentrations were measured, dilution series were performed, and 1st-step PCRs were set up. In the 1st-step PCR, primer amplifying different V-regions were used (e.g., V1-V2, V3-V4, and V7-V9). Products were cleaned and used as a template for the 2nd-step PCR. Primers used include barcodes and the Illumina sequencing primer (P5 and P7). The resulting amplicons were again cleaned and it was checked whether the desired library size could be observed on agarose gels. The detection limit of the used GelRed dye is reported to be about $100 \mathrm{pg}$ (Biotium, https://biotium.com/faqs/category/gelred-gelgreen/). 
However, it should be kept in mind that the actual limit depends on the used instrument's capability and exposure settings. Sharp and conclusive bands were observable with our equipment and settings for at least $2-5 \mathrm{ng}$ product loaded. For establishing the protocol, amplicons of the 2nd-step PCRs were diluted according to Formula (1), such that approximately one amplicon molecule is finally present per droplet. Next, ddPCR mixes were produced. The primers for the ddPCR used were plain P5 and P7 primers, which allow the re-amplification of the templates generated thus far. The final ddPCR amplicons were extracted and checked for adequate concentrations allowing $16 \mathrm{~S}$ rRNA gene sequencing. If concentrations were still too low, which was the case for samples conducted using less than $50 \mathrm{pg}$ initial DNA, the isolated amplicons were re-amplified in a standard PCR but using a Q5U polymerase with primer P5 and P7. This we referred to as "emergency plan", since this additional step was able to "rescue" samples which otherwise would have failed in sequencing. In any case, all samples were sequenced on an Illumina MiSeq and compared.

\section{Determination of detection limits in standard 16S rRNA gene sequencing approaches}

For all samples of the control experiment, products were detectable using agarose gels after the 2nd-step PCR. For the dilution series experiment, bands corresponding to the desired product were only visible for DNA inputs $\geq 5 \mathrm{ng}$ total DNA, irrespective of which primers were used for amplification. After the ddPCR, bands could be observed on agarose gels for all samples amplified with primers targeting V7-V9. For V1-V2 samples, clear bands were visible for input amounts $\geq 50 \mathrm{pg}$. The detection limit for V3-V4 samples was higher; bands could only be detected for input amounts $\geq 500 \mathrm{pg}$ for all samples, while some samples produced products at $100 \mathrm{pg}$ already (Table 1).

If no band could be observed for a sample after ddPCR had been performed, re-amplification of the (invisible) product was conducted (marked as 'emergency plan' in Fig. 1). Importantly, re-amplification was only possible when an uracil-tolerant polymerase, e.g., Taq polymerase or a U-tolerant proofreading polymerase such as Q5U (NEB) or Phusion U Hot Start DNA Polymerase (Thermo Fisher) was used. The QX200 EvaGreen supermix contains some amounts of dUTP, causing ddPCR products to contain uracil subsequently. dUTP is used to allow the destruction of carry-over products from previous PCRs using Uracil-N-Glycosylase in the PCR mixture [48]. In any case, re-amplification with normal proof-reading polymerases such as the Phusion (Thermo Fisher) is inhibited and products can only be re-amplified with the mentioned U-tolerant polymerases.

The number of final sequenced reads, irrespectively of which approach was used, varied between 11,298 to 118,212 reads per sample with an average of 42,754 reads. The average read number of the negative controls was 506.

\section{Control experiment to assess the potential bias of the ddPCR step}

In a first experimental setup, we assessed whether the integration of a ddPCR step after the 2nd-step PCR used for barcoding showed a bias on the $\beta$-diversity and the resulting taxonomical profiles of the samples. Ideally, samples originating from the same human donor, or the same mock community should not show any or only minor differences. We screened, therefore, four human samples (T1, T28, T29, T30) and two mock communities of known composition. The latter show different amounts of complexity as they are either composed of 8 different

Table 1 Visibility of bands corresponding to desired PCR products observed on 1.5\% agarose gels. Green tick: bands were visible for all tested samples, yellow tick in brackets: bands were weak and/ or not visible for all tested samples. Red x: bands were not visible for none of the tested samples

\begin{tabular}{|c|c|c|c|c|c|c|c|}
\hline & & \multicolumn{3}{|c|}{ Gel after $2^{\text {nd }}$ step PCR } & \multicolumn{3}{|c|}{ Gel after ddPCR } \\
\hline Total DNA input & V-region amplified & $\mathrm{V} 1-\mathrm{V} 2$ & V3-V4 & V7-V9 & V1-V2 & V3-V4 & V7-V9 \\
\hline $60 \mathrm{ng}$ & & $\checkmark$ & $\checkmark$ & $\checkmark$ & $\checkmark$ & $\checkmark$ & $\checkmark$ \\
\hline $12 \mathrm{ng}$ & & $\checkmark$ & $\checkmark$ & $\checkmark$ & $\checkmark$ & $\checkmark$ & $\checkmark$ \\
\hline $10 \mathrm{ng}$ & & $\checkmark$ & $\checkmark$ & $\checkmark$ & $\checkmark$ & $\checkmark$ & $\checkmark$ \\
\hline $5 \mathrm{ng}$ & & $\checkmark$ & $\checkmark$ & $\checkmark$ & $\checkmark$ & $\checkmark$ & $\checkmark$ \\
\hline $1 \mathrm{ng}$ & & $x$ & $x$ & $x$ & $\checkmark$ & $\checkmark$ & $\checkmark$ \\
\hline $500 \mathrm{pg}$ & & $x$ & $x$ & $x$ & $\checkmark$ & $\checkmark$ & $\checkmark$ \\
\hline $100 \mathrm{pg}$ & & $x$ & $x$ & $x$ & $\checkmark$ & $(\sqrt{ })$ & $\checkmark$ \\
\hline $50 \mathrm{pg}$ & & $x$ & $x$ & $x$ & $\checkmark$ & $x$ & $\checkmark$ \\
\hline $10 \mathrm{pg}$ & & $x$ & $x$ & $x$ & $(\checkmark)$ & $x$ & $\checkmark$ \\
\hline
\end{tabular}


bacterial genera (Zymo mock community) or 18 different genera (ZIEL2 mock community). We further sequenced the samples using three different primer pairs amplifying V1-V2, V3-V4, and V7-V9.

Comparing the results, we found that the differences introduced by using different primer pairs for the different V-regions caused profiles to be more distinct from each other than differences introduced by either the preparation method (standard protocol, marked as Sample-C in Fig. 2, vs. protocol with additional ddPCR, marked as Sample-D in Fig. 2). When clustering was performed on genus level, samples clustered by their origin (i.e., samples originating from the same donor cluster close to each other, even when amplified using different primer pairs). Concerning the latter, the difference between the tested samples (T1, T28, T29, T30, Zymo, and ZIEL2) was significant with a $p$-value of $\leq 0.001$ tested with PERMANOVA (Fig. 2A). More importantly, we could demonstrate that the additional ddPCR had a smaller effect on the sample clustering than the use of different primer pairs (Fig. 2B). Further, the additional procressing step did not lead to significant differences in final sample composition as only minor shifts in the resulting taxonomical profiles of the samples were observed when control (samples-C) and ddPCR processed samples (samples-D) were compared (Fig. 2C). When comparing samples-C to samples-D in richness, we do not see a significant deviation in alpha-diversity. The resulting adjusted $p$-value found for the comparison of C-/D-samples was $\mathrm{p}_{\text {adj. }}=0.99$. The Zymo mock community performed overall well (Fig. 2D), regardless of which V-region was targeted. For the more complex ZIEL2 mock community (Fig. 2E), we could show by calculating the generalized UniFrac distances against the ideal composition that the most accurate representation was produced by targeting the V3-V4 regions (see Supplementary Table 1).

\section{Estimation of minimal DNA input amounts for reliable 16S rRNA gene sequencing}

In a second experimental set-up, dilution series of different total DNA input amounts were tested for the lowest DNA input possible producing reliable taxonomic profiles of human samples or mock communities. As before, samples were amplified using three different primer pairs.
As shown in Table 1, detection limits varied for different V-regions. Thus, the taxonomic composition of each sample was checked for differences from either the actual composition in the case of mock communities or the taxonomical profiles achieved amplifying high initial DNA amounts in the case of the human samples. For the Zymo mock community, we found that Gram-negative bacterial genera such as Escherichia, Pseudomonas, or Salmonella were increasingly overestimated with descending DNA amounts used, while Gram-positive bacterial genera, e.g., Lactobacillus, Listeria, or Staphylococcus were progressively underestimated. When analyzing the ZIEL2 mock, primer-dependent issues became more prominent, which has been observed before [8]. In contrast to the Zymo mock community, no clear tendencies concerning different genera could be observed for the human samples despite the increase of spurious sequencing reads arising in very diluted samples (combined in "other").

For V3-V4 and V7-V9, deviations from the expected composition become more apparent with increasingly less DNA used as initial input (Fig. 3). For instance, amounts of 50 and $10 \mathrm{pg}$ DNA did not always produced reliable results when taxonomical profiles at genus-level were analyzed. For the highly diluted Zymo mock, we observed increasing numbers of reads not representing members of the original mock community. Overall, for Zymo mock, the average amount of reads not corresponding to the expected bacteria was $0.9 \%$. For V1-V2, the median amount of off-target reads for samples of $60 \mathrm{ng}$ to $50 \mathrm{pg}$ was $0.24 \%$ and for $10 \mathrm{pg}$ input $1.27 \%$. For V3-V4 and V7-V9, a drastically increased number of reads not matching the mock could be identified when using $10 \mathrm{pg}$ input DNA. The average amount for off-target sequences was 0.19 and $0.24 \%$ for V3-V4 and V7-V9 respectively, of all reads concerning input amounts varying between $60 \mathrm{ng}$ to $50 \mathrm{pg}$. The number of off-target reads for $10 \mathrm{pg}$ samples reached 8.8 and $7.1 \%$ for $\mathrm{V} 1-\mathrm{V} 2$ and V7-V9, respectively. For human sample T1, $10 \mathrm{pg}$ DNA input was not sufficient when targeting V3-V4. Deviations from the expected taxonomic profile are apparent for this low amount of input DNA used (Fig. 3). Thus, it seems that detection limits are not only V-region specific but also dependent on each sample. For instance, for T30 reliable profiles with just $10 \mathrm{pg}$ input DNA

(See figure on next page.)

Fig. 2 Control experiment to test for bias possibly introduced due to the extra ddPCR step after 2nd-step PCR. Samples processed with ddPCR (Samples marked "D" for ddPCR processed, 12 ng DNA used) are compared to standard short amplicon controls which were not ddPCR processed (Samples marked "C" for Control, 12 ng DNA used). Four human samples: T1 (red), T28 (orange), T29 (green), T30 (turquoise) and two mock communities: Zymo (pink), ZIEL2 (blue) were sequenced using primer pairs amplifying different V-regions. A Meta Multi-Dimensional Scaling (MDS) shows that samples cluster significantly differently due to their origin and not by preparation method. B The dendrogram shows that clustering is dependent on sample origin even though clustering within a sample is effected by the V-region targeted. C Taxonomic profiles at genus-level of Sample-C and Sample-D for human samples. D As before, for mock samples from Zymo and (E) and ZIEL2. Note, the taxonomic profiles at the genus-level show only minor differences when the same $V$-region is targeted 
A

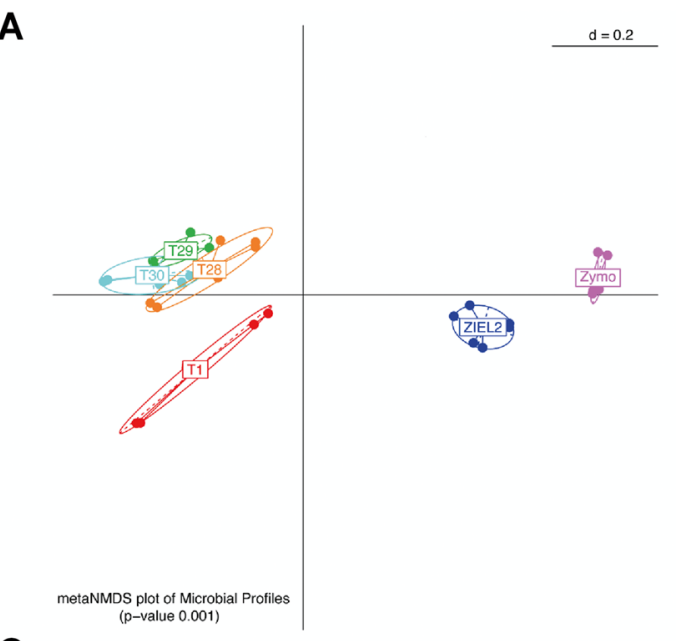

B

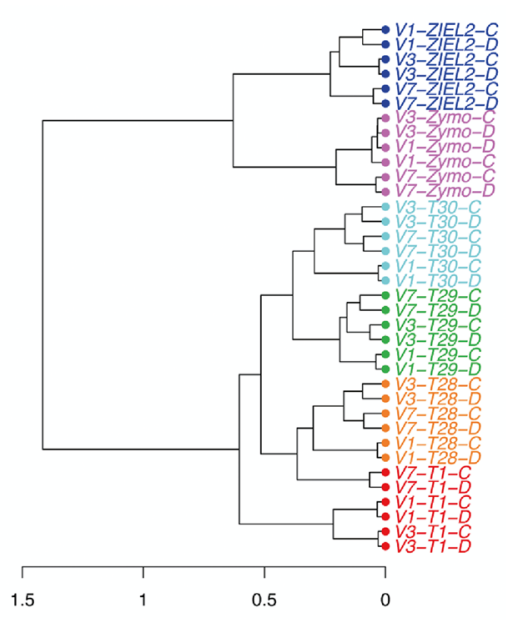

V7-v9

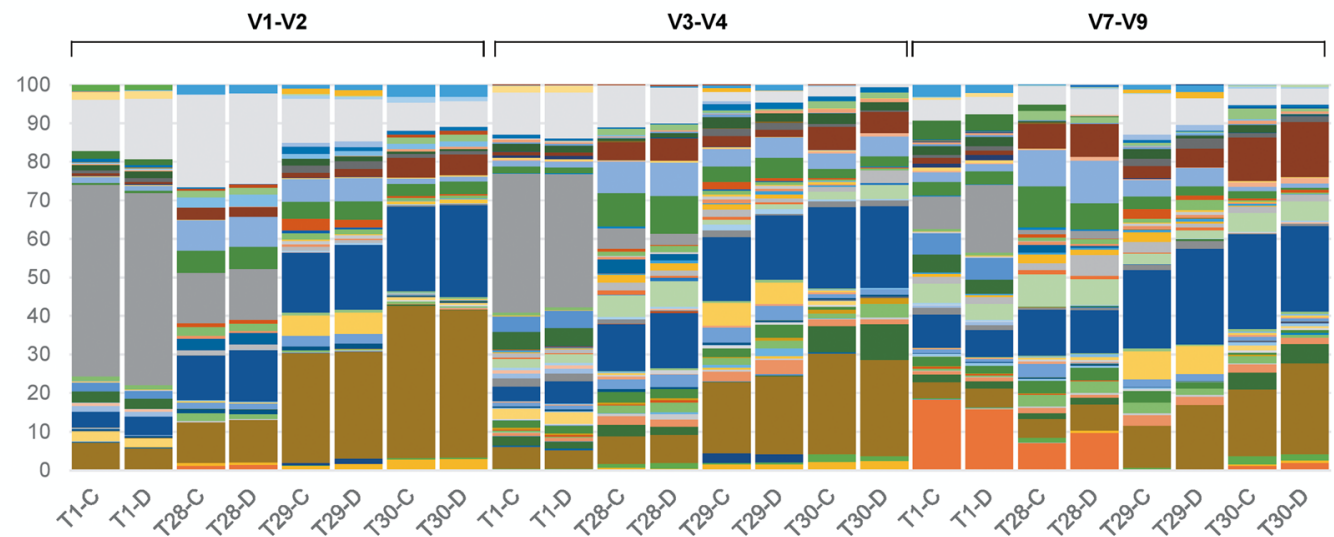

-Adlercreutzia
- Anaerostipes
- Barnesiella

- CAG-352
Colidextribacter
- Cutibacterium

- Eutibacterium

- Escherichia-Shigella - GCA-900066575 Intestinibacter
- Lachnospiraceae ND3007
- Leuconostoc - Megasphaera
- Oscilibacter Pseudomonas
Ruminococcus - Rubdoligranulum - UCG-003 unknown_Clostridia UCG-014 unknown_Eubacterium - unknown Prevotellaceae - Asteroleplasma - Bifidobacter
- $A A G-56$

- Collinsella
Desulfovibrio

- Enterobacter

- Eubacterium eligens

- Granulicatella

Klebsiella
- Lachnospiraceae NK4A136

- Lachnospira

- Mitsuokella

- Parabacteroides

- Romboutsia

- Suminella
SUCG-005

- unknown_Clostridia vadinBB60 - unknown_Fimicutes
unknown_Oscillospiraceae -unknown_Rhodospirillales

D

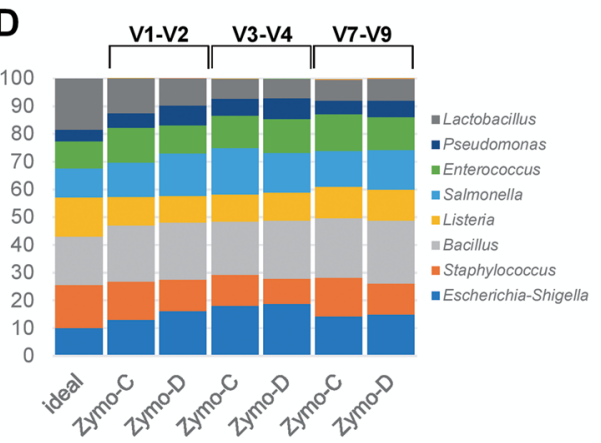

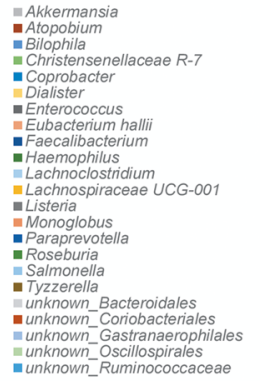

=Alistipes

Bacillus

- Coprococcus

Dorea

- Erysipelatoclostridium

(nentium

Holdemanella

- Lachnospira
- Lachnospiraceae UCG-004
Marvinbryantia

NK4A214 group

- Ruminococcus

Staphylococc
UBA1819

unknown_Barmesiellaceae

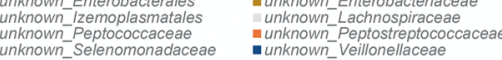

- Alloprevotella

- Butyricicoccus

- Clostridium sensu stricto 1
- Coriobacteriaceae UCG-003

- Eggerthella

-Eubacterium sirae
Fusicatenibacter

- Incertae Sedis

- Lachnospiraceae FCSO2O

- Lactobacillus

- Odoribacter

- Prevotella

nococcus gauvreauii

- Streptococo

- unknown_Clostridia

- unknown Lachnospiraceae
unknown Peptostreptococcaceae

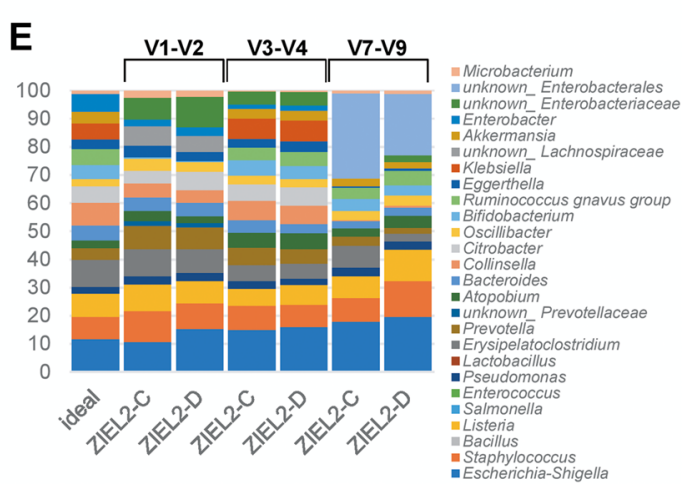

Fig. 2 (See legend on previous page.) 


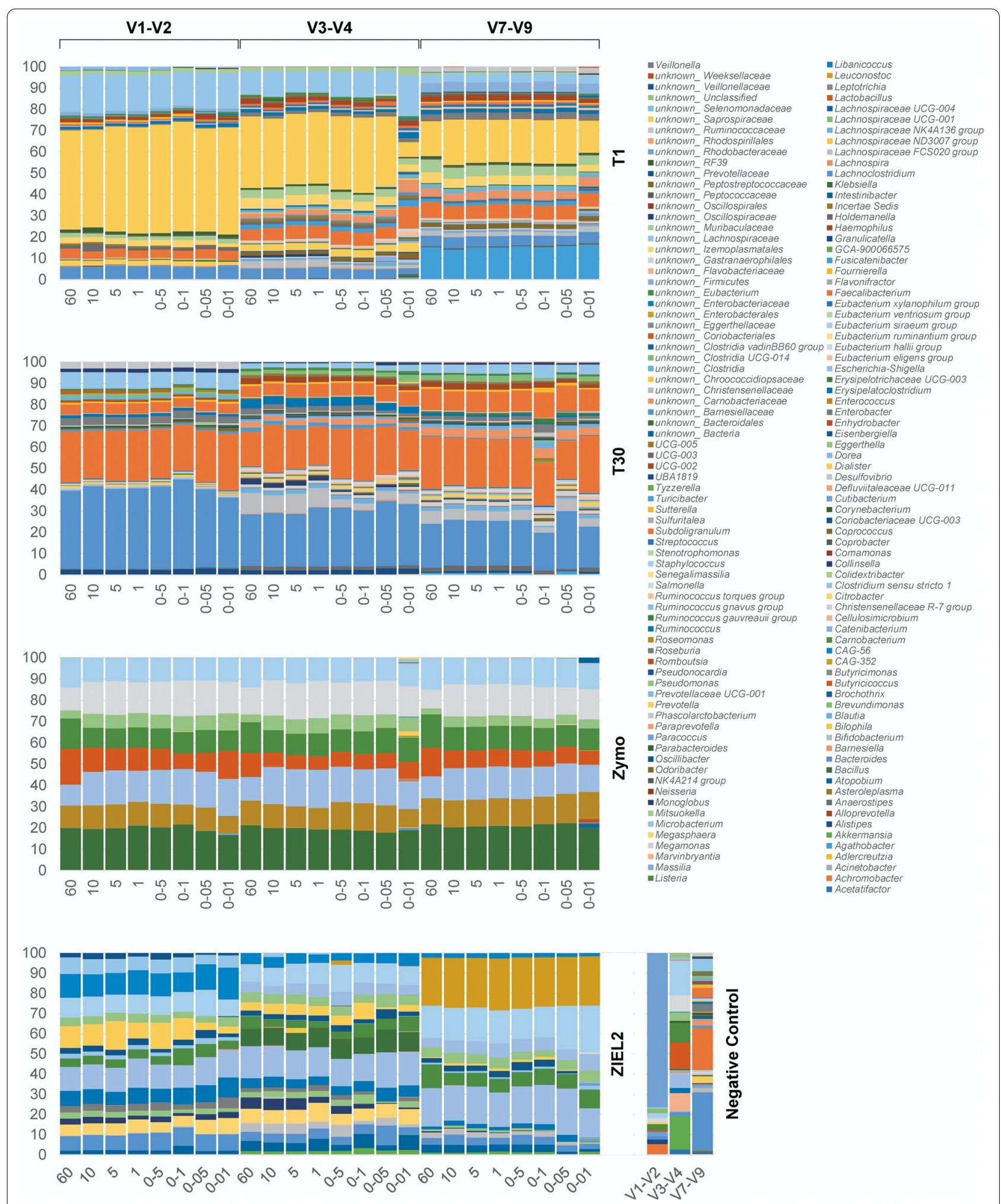

Fig. 3 Taxonomical profiles at the genus level for two human samples (T1,T30) and two mock communities of known composition (Zymo, ZIEL2). For every sample, different initial DNA amounts were used for 1st-step PCRs and, further, different V-regions were targeted 
targeting V3-V4 were produced, while $\mathrm{T} 1$ failed for the same combination and needed at least $50 \mathrm{pg}$ input DNA. To verify reproducibility, we repeated the dilution series for T1, T30, and the Zymo mock community targeting V3-V4, which performed worst in the first experimental setup compared to V1-V2 and V7-V9. Only amplicons from using concentrations $\geq 100 \mathrm{pg}$ produced reliable and repeatable results in the independent repetition (Supplementary Fig. 1).

\section{Proof of concept using water body samples}

To demonstrate that the proposed method is applicable to real low-biomass samples, we performed a proof-ofconcept study using water body samples. Ten samples from different ponds and rivers near Freising, Germany (Fig. 4A) were collected. We analyzed the DNA of plain $15 \mathrm{ml}$ water each. As controls, two MilliQ water samples and a desalted lab water sample were included accordingly and treated as the other water body samples.

At first, the standard 16S rRNA sequencing protocol was applied (1st-step PCR with 15x cycles and 2ndstep PCR with 10x cycles). The resulting amplicons were checked on an agarose gel for appearance of a band at around $600 \mathrm{bp}$ of size. None of the water samples presented a visible band at the desired size. Moreover, after the purification with AMPure XP Beads, concentrations could only be determined for four out of the 13 samples and controls. Furthermore, the measured concentrations were with between $0.05 \mathrm{ng} / \mu \mathrm{l}$ to $0.09 \mathrm{ng} / \mu \mathrm{l}$; thus, too low for the 16S rRNA gene sequencing. Next, we tested whether a simple re-amplification would result in sufficient products for all samples tested. Here, a standard P5-P7 PCR (15x cycles) was performed. However, even after re-amplification, no bands could be observed for any of the samples and neither for the controls. Resulting amplicon concentrations were still too low for most of the samples (data not shown). Therefore, we applied our proposed protocol. The 2nd-step PCR products were diluted and ddPCR processed. For all samples, except the controls (cleaned water samples: desalted lab water, MilliQ1 and MilliQ2) amplicons could be observed after the ddPCR. Concentrations ranged from $0.3 \mathrm{ng} / \mu \mathrm{l}$ to $4.2 \mathrm{ng} /$ $\mu \mathrm{l}$ for the water body samples and 0.1 to $0.2 \mathrm{ng} / \mu \mathrm{l}$ for the controls. Sequencing was performed and the resulting analysis showed that we obtained for all water body samples useful results, which was not the case before. In all cases, the water body samples were more diverse compared to the control samples, which consisted of two MilliQ and a desalted lab water sample (Fig. 4B). For instance, all water body samples cluster significantly apart from the control samples in a metaNMDS plot (Fig. 4C). As expected, richness was significantly higher in any of the water body samples compared to the water controls. Further, we found that for example, Limnohabitans was present in all water body samples but not in the control samples (Fig. 4D). This bacterium is known to be in various numbers an important part for many freshwater habitats [49].

\section{Discussion}

In this study it was investigated, how to obtain reliable $16 \mathrm{~S}$ rRNA sequencing-based taxonomies even with very low input amounts of initial DNA. We found that the introduction of a ddPCR step after standard PCR-based library production allowed using low-DNA concentrated samples. The ddPCR enabled to successfully and reliably re-amplify $16 \mathrm{~S}$ rRNA amplicons from the foregone PCR steps, even if they were not detectable in gel electrophoreses nor measurable using a Qubit. The minimal DNA input amounts successfully used in this study for samples processed were $50 \mathrm{pg}$ DNA (equating to $1 \mathrm{pg} /$ $\mu \mathrm{l}$ in the 1st-step PCR mix) for samples targeted using primers amplifying regions V1-V2 and V7-V9 and $100 \mathrm{pg}$ DNA (equating to $5 \mathrm{pg} / \mu \mathrm{l}$ in the 1st-step PCR mix) for V3-V4. In contrast, Multinu, et al. [27] stated that the minimal concentrations of DNA input should be between 40 to $200 \mathrm{pg} / \mu \mathrm{l}$. Further, Velásquez-Mejía, et al. [37] suggested to use at least $500 \mathrm{pg} / \mu \mathrm{l}$ DNA. Thus, we needed a maximum of at least 8-times less and often even lesser input amounts compared to these studies. Moreover, we could not confirm some of the other observations made by those groups. Multinu, et al. [27] described an overrepresentation of Proteobacteria and an underrepresentation of Firmicutes for low DNA input samples. When using ddPCR, no such general trend became obvious when analyzing human samples. For instance, for sample T1, the deviations between high and low DNA input were dependent on the targeted region, rather than on the amount of input DNA. When sample T1 was amplified using 27F and 338R primer (V1-V2), we could identify a reduction in Firmicutes and Proteobacteria for samples with lower DNA input amounts, whereas Bacteroidetes seemed to be overrepresented when using low DNA amounts. When V3-V4 was targeted in T1, Firmicutes and Proteobacteria seemed to be overrepresented and Bacteroidetes underrepresented. Concerning V7-V9, we saw no distinct change in Firmicutes or Proteobacteria amounts but an overrepresentation in Bacteroidetes for $\mathrm{T} 1$ (data are summarized in Supplementary Table 2). Even more, for T30, the trends do neither follow the shifts we saw for T1 nor those described by Multinu, et al. [27]. Generally, the phyla-level composition seems to be more inconsistent for T30 than for T1 when analyzing a dilution series within one targeted region (see Supplementary Table 3). 


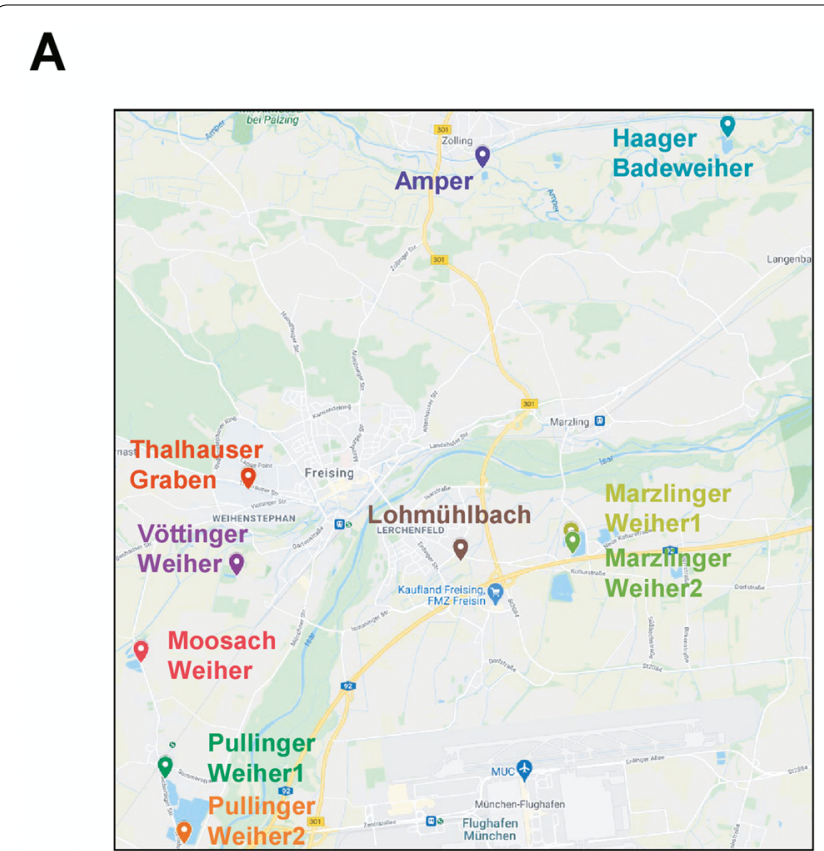

\section{C}

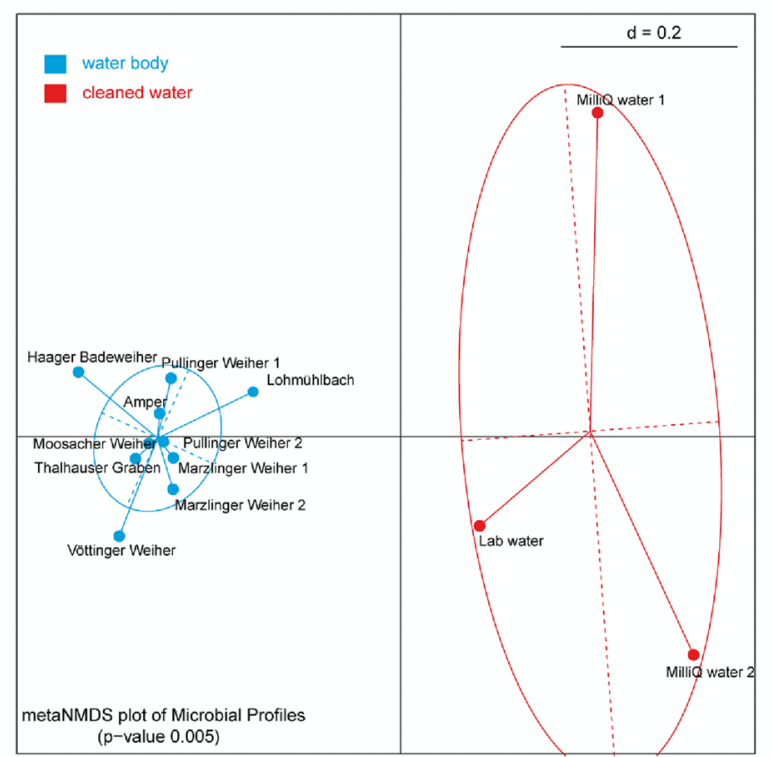

\section{B}

Rarefaction Curves
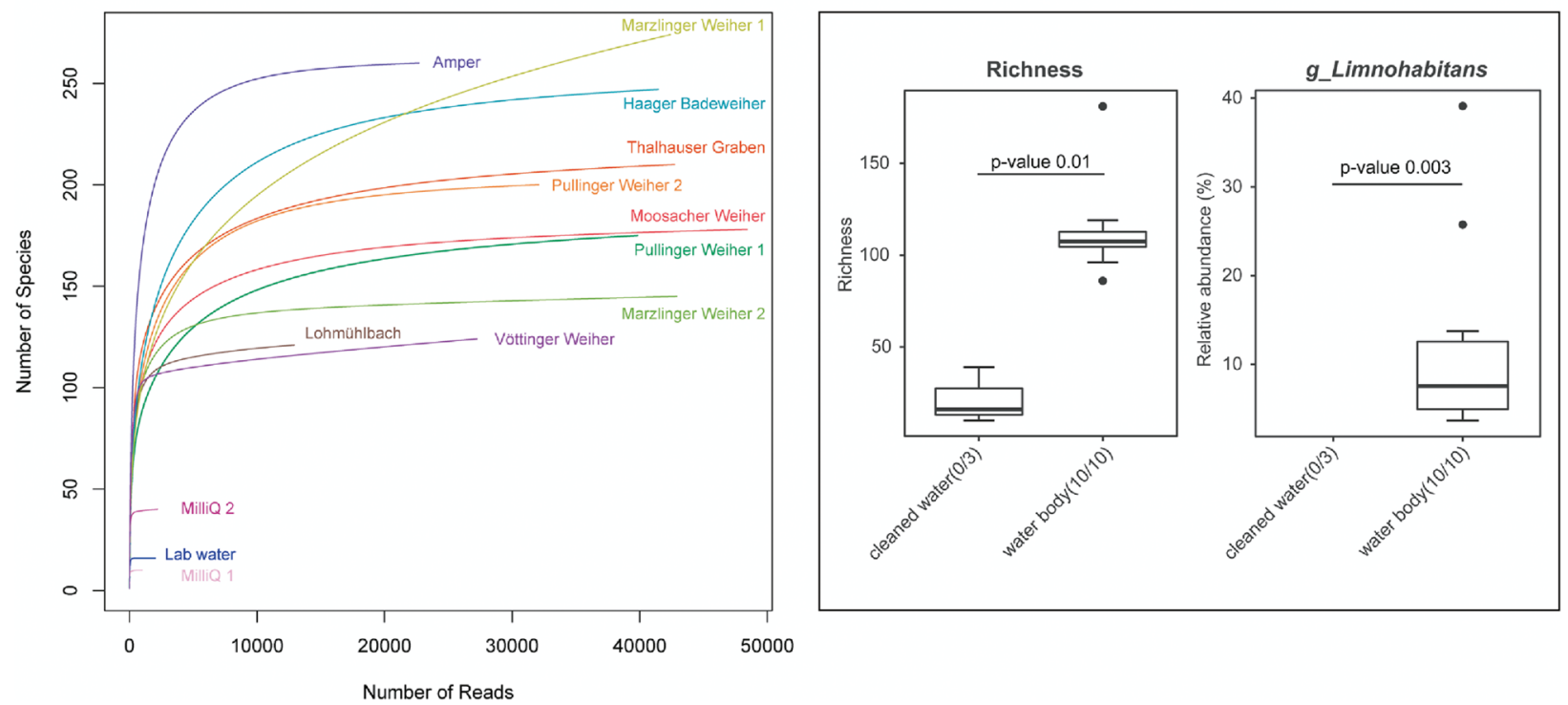

Fig. 4 Proof of concept study for low biomass samples using water of ponds and rivers. A Ten different samples were selected from water bodies in and around the city of Freising, Germany. The map was provided by GoogleMaps. B The rarefaction curve shows that cleaned water samples (MilliQ and desalted water samples) have significantly lower number of reads and species compared to all other water body samples. C The multi-dimensional scaling (MDS) plot shows that cleaned water samples ('control') cluster significantly apart from the water body samples. D Significant differences were found when comparing the water body samples to the controls for richness or, e.g., the abundance of the genus Limnohabitans

We conclude that the variation and shift in taxonomical compositions are mainly driven by using different primer pairs. This biasing factor was already intensively studied previously (e.g., $[8,9,11,50])$. However, some further bias of under- or overrepresented taxa also is introduced due to distinct starting DNA concentrations. Here, we demonstrated that using ddPCR in case of limited input amounts (versus Control) had not a significant impact. 
Instead, samples cluster due to their origin, as wanted, but indeed also with the V-region(s) targeted, concurring with the above mentioned primer bias.

Human stool samples of healthy persons are not of low biomass. Nonetheless, we needed a sample type allowing using high and low DNA concentrations for comparison. The human stool samples should be only interpreted with some caution. We do not know the exact bacterial composition of these samples. However, in our proof of concept, we showed that the proposed method allows sequencing environmental samples, which are indeed of low biomass.

Interestingly, most of the commonly used protocols use high or even very high amounts of DNA in their protocols. To list only some examples: the Zymo Quick 16S NGS Library Prep Kit (Zymo Research Europe $\mathrm{GmbH}$, Freiburg, Germany) aims for about 40ng DNA that is free of PCR inhibitors; the QIAseq 16S kit (Qiagen, Hilden, Germany) recommends amounts of $12.5 \mathrm{ng}$, and the lowest amount usable is given with $1 \mathrm{ng}$, which is at least 20-fold higher compared to our protocol. Further, in the NEBNext Ultra DNA Library Prep kit (New England Biolabs, Ipswich, USA) for Illumina, $500 \mathrm{pg}$ to $1 \mu \mathrm{g}$ of input DNA is recommended. In this proofof-principle study, we show that very-low initial DNA concentrations, which are by far lower than the recommended input amounts listed above, can be successfully sequenced, and reliably analyzed when implementing a ddPCR step. This is of special interest for low-bacterial biomass samples, such as milk, water samples, pathological or clinically relevant human samples including sputum, infant stool, biopsies, and others. While several $16 \mathrm{~S}$ rRNA gene sequencing optimization protocols for such samples were already published (e.g., [31-35]), these studies aim at changing the parameters of existing protocols or try to reduce contamination sources in order to obtain taxonomic profiles of low-biomass samples. In contrast, ddPCR, which has to our knowledge not been applied to improve sequencing of low biomass samples, has only to be added at the end of a commonly used $16 \mathrm{~S}$ rRNA gene sequencing protocol. While ddPCR methods were already described for quantification of microbial species or communities [39, 42, 51-53], to our knowledge, resulting PCR products were rarely re-extracted from the oil-aqueous suspensions for further use. Here we demonstrate that these products can be successfully sequenced, producing reliable taxonomic profiles. Even taking this a step further, these products can be reamplified after ddPCR (e.g., in case of still too low concentrations), but uracil accepting polymerases must be used for following this "emergency plan".

\section{Conclusions}

Taken together, ddPCR, which splits the reaction volume in about 20,000 droplets, allows faithful amplification even of low amounts of template. Thus, sequencing of samples of low bacterial biomass (e.g., of a sick person with low bacterial loads), currently not easily accessible, can now be sequenced and compared with control samples of healthy persons with high amounts of bacteria. Besides, in order to improve comparability between publications it is important to always state the DNA concentrations and volumes used. Negative controls indicating possible shifts in taxonomical profiles are imperative. Finally, results produced by using different primer pairs cannot be easily compared.

\section{Methods}

\section{Preparation of human gut samples}

Stool samples were obtained from healthy volunteers of age after informed and written consent. An ethics approval is deemed unnecessary according to the statement given in the Drucksache 15/2849 of the German Bundestag about $\mathbb{\$} 41$ Abs. 2 Nr. 2 S. 1 and 2 Arzneimittelgesetz. Stool samples collected in stool sample tubes as described previously by Abellan-Schneyder, et al. [8].

\section{Extraction of DNA from stool samples}

The DNA was isolated using a modified protocol by Godon, et al. [54] as described previously by Reitmeier, et al. [38] and Abellan-Schneyder, et al. [8].

\section{Extraction of DNA from mock communities}

DNA of the Zymo mock community was purchased as a ready-to-use DNA mock (D6306, Zymo Research). The ZIEL2 mock community was prepared and extracted as described in Abellan-Schneyder, et al. [8]. In brief, every 19 bacterial strains (18 different bacterial genera) of diverse taxonomy were cultured and afterward harvested by centrifugation. Genomic DNA extraction was performed separately for each strain. For the ZIEL2 mock community DNA mixture, $12 \mathrm{ng}$ of each bacterial DNA was pooled.

\section{Preparation of water samples}

For each water body sample, at first $50 \mathrm{ml}$ fresh water were collected in sterile falcon tubes and transported immediately to the lab. An ethanol precipitation was performed as previously described by Foote, et al. [55]. In brief, for each sample, $15 \mathrm{ml}$ water were precipitated using $33 \mathrm{ml} 100 \% \mathrm{EtOH}$ and $1.5 \mathrm{ml} 3 \mathrm{M} \mathrm{NaOAc}$ at $-80^{\circ} \mathrm{C}$ for $2 \mathrm{~h}$. Samples were centrifuged at $10,000 \times g$ for $10 \mathrm{~min}$. The supernatant was discarded, the pellets were washed once with $80 \% \mathrm{EtOH}$ and DNA extraction was performed 
using the same protocol as above. For the 1st-step PCR, $10 \mu \mathrm{l}$ undiluted extracted DNA sample were used. The 1st- and 2nd-step PCR were performed as described below and PCR products were visualized after the 2ndstep PCR. The concentrations were determined on a Qubit 4.0 (Thermo Fisher) and dilutions were performed accordingly as described below.

\section{Determination of concentration and dilution of DNA input} Initial sample concentrations were measured in triplicates on a Qubit 4.0 (Thermo Fisher). According to the initial concentrations, stock solutions of $10 \mathrm{ng} / \mu \mathrm{l}$ and $1 \mathrm{ng} / \mu \mathrm{l}$ were set up and again measured in triplicates on a Qubit 4.0 (Thermo Fisher). The following dilution series, to reach the desired final concentrations (Table 2) were performed in $0.5 \mathrm{ml}$ LoBinding Tubes (Eppendorf). After each dilution step, samples were briefly vortexed and spun down on a mini centrifuge.

\section{Amplicon preparation}

For amplification of the variable regions and addition of adapters, a 1st-step PCR was performed in $50 \mu \mathrm{l} \mathrm{vol-}$ ume containing $10 \mu \mathrm{l}$ DNA (total amounts are detailed in Table 1), $1 \times$ Phusion HF buffer, $0.2 \mathrm{mM}$ dNTPs, $0.125 \mu \mathrm{M}$ of each fw_primer and rv_primer, $7.5 \%$ DMSO and $0.25 \mu$ l of Phusion HF II DNA polymerase (Thermo Fisher). PCR was performed as followed: $98^{\circ} \mathrm{C}$ for $40 \mathrm{~s}$, followed by 15 cycles of $98^{\circ} \mathrm{C}$ for $20 \mathrm{~s}$, V-region specific

Table 2 Concentrations and dilutions of DNA input used for 1st-step PCR reaction

\begin{tabular}{lll}
\hline Name & Total input DNA (ng) & $\begin{array}{l}\text { Final DNA concentration } \\
\text { in } 50 \boldsymbol{\mu l} \text { PCR reaction }(\mathbf{p g} / \\
\boldsymbol{\mu l})\end{array}$ \\
\hline 60 & & 1200 \\
12 & 60 & 240 \\
10 & 12 & 200 \\
5 & 10 & 100 \\
1 & 5 & 20 \\
0.5 & 1 & 10 \\
0.1 & 0.5 & 2 \\
0.05 & 0.1 & 1 \\
0.01 & 0.05 & 0.2 \\
\hline
\end{tabular}

annealing temperature (Table 3) for $40 \mathrm{~s}$ and $72^{\circ} \mathrm{C}$ for $40 \mathrm{~s}$, followed by a final extension step at $72^{\circ} \mathrm{C}$ for $2 \mathrm{~min}$. The structure of the primers was $5^{\prime} \rightarrow 3^{\prime}$ : "overhang $[\mathrm{N}]_{15}-16 \mathrm{~S}$ specific sequence" for the 1st-step and "P5/ P7-8 bp Barcode - overhang" for the 2nd-step PCR. To enable multiplexing, barcodes were added in a 2nd-step PCR. Here, a $100 \mu \mathrm{l} \mathrm{PCR} \mathrm{was} \mathrm{prepared} \mathrm{using} 10 \mu \mathrm{l}$ of the 1st-step PCR product, $1 \times$ Phusion HF buffer, $0.2 \mathrm{mM}$ dNTPs, $0.125 \mu \mathrm{M}$ of each $\mathrm{fw}_{-}$barcode and rv_barcode primer, $0.25 \%$ DMSO, and $0.5 \mu \mathrm{l}$ of Phusion HF II DNA polymerase. PCR conditions were $98^{\circ} \mathrm{C}$ for $40 \mathrm{~s}, 10$ cycles of $98^{\circ} \mathrm{C}$ for $20 \mathrm{~s}, 55^{\circ} \mathrm{C}$ for $40 \mathrm{~s}$ and $72^{\circ} \mathrm{C}$ for $40 \mathrm{~s}$ as well as a final extension step at $72^{\circ} \mathrm{C}$ for $2 \mathrm{~min}$. Further details, e.g. work time estimations can be found in the work of Reitmeier, et al. [38].

\section{Library quality check}

For validation and quality assurance, $8 \mu \mathrm{l}$ of 2 nd-step PCR product were loaded on a $1.5 \%$ agarose gel to perform gel electrophoresis. The remaining $92 \mu \mathrm{l}$ of the 2nd-step PCR were purified with $0.6 \times$ AMPure XP beads. Concentrations of the 2nd-step PCR product were measured in triplicates using a Qubit 4.0.

\section{Digital droplet PCR}

Amplicons generated in the two-step PCR (above) were amplified again using P5 and P7 primers in a ddPCR. At first, each sample was diluted to a concentration of approx. 20,000 copies/20 $\mu$ l calculated by the Formula (1). The average library sizes were $486 \mathrm{bp}$ for V1-V2, $602 \mathrm{bp}$ for V3-V4, and 547 bp for V7-V9. Dilution series must be performed in LoBind tubes (Eppendorf) and in 1:10 steps to guarantee precise dilutions.

$$
\frac{660 \frac{\mathrm{g}}{\mathrm{mol}} \times \text { average library size }[\mathrm{bp}]}{6,022 \times 10^{23} \mathrm{~mol}^{-1}} \times 10^{9} \times \frac{20000}{20 \mu \mathrm{l}}=\text { concentration }\left[\frac{\mathrm{ng}}{\mu \mathrm{l}}\right]
$$

The composition of the reaction mixture for the ddPCR was as follows: $1 \times$ QX200 ${ }^{\mathrm{TM}}$ EvaGreen ${ }^{\circledR}$ Supermix, $0.1 \mu \mathrm{M}$ of P5 (forward) and $0.1 \mu \mathrm{M}$ of P7 (reverse) primer, $2.5 \mu \mathrm{l}$ DNA sample (1000 copies/ $\mu$ l) and water up to $25 \mu$ l. These ingredients were mixed thoroughly by vortexing and $20 \mu \mathrm{l}$ of the mixture was transferred into a $\mathrm{DG}^{\mathrm{TM}}$ Cartridge for the QX200 Droplet generator. Next, $70 \mu \mathrm{l}$ of

Table 3 Variable region-specific forward and reverse primers and annealing temperature for 1st-step PCR

\begin{tabular}{lllll}
\hline Region & Forward primer & Reverse primer & $\begin{array}{l}\text { Annealing } \\
\text { temperature }\end{array}$ & Reference \\
\hline V1-V2 & AGA GTT TGA TYM TGG CTC AG & GCT GCC TCC CGT AGG AGT & $57^{\circ} \mathrm{C}$ & Salter, et al. [28] \\
V3-V4 & CCT ACG GGN GGC WGC AG & GACTAC HVG GGT ATC TAA TCC & $55^{\circ} \mathrm{C}$ & Klindworth, et al. [10] \\
V7-V9 & CAA CGA GCG CAA CCC T & GGT TAC CTT GTT ACG ACTT & $51^{\circ} \mathrm{C}$ & Turner, et al. [62] \\
\hline
\end{tabular}


QX200 Droplet Generator Oil for EvaGreen was transferred into the oil well of the cartridge. Then a gasket was spanned over the cartridge and droplets were produced by the droplet generator following the Droplet Generator Instruction Manual (BioRad). Droplets were then transferred to a 96-well plate. Before starting the PCR in a thermocycler, the plate was sealed with a pierceable PCR Plate Heat Seal Foil (BioRad) using a PX1 PCR Plate Sealer (BioRad). PCR was performed in a PeqStar thermocycler (PeqLab) using cycling conditions as described in Table 4.

The PCR products were recovered for further use of the amplicons. Each reaction was transferred into a clean $1.5 \mathrm{ml}$ LoBind DNA tube (Eppendorf) and the lower oil phase (the specific oil is heavier than water) was discarded by pipetting. After adding $20 \mu \mathrm{L} 1 \times$ TE buffer and $70 \mu \mathrm{l}$ chloroform to the remaining aqueous phase, mixtures were vortexed for $1 \mathrm{~min}$ at high speed in a 2-ml adapter for the Vortex-Genie 2 (Thermo Fisher) and centrifuged at $15,500 \times \mathrm{g}$ for $10 \mathrm{~min}$. The upper aqueous phase (volume approx. $25 \mu \mathrm{l}$ ), containing amplicons, was separated by pipetting. Samples were purified using $1 \times$ AMPure XP beads and eluted in $20 \mu \mathrm{l} \mathrm{H}_{2} \mathrm{O}$. The concentration was determined using the Qubit dsDNA HS Assay (Invitrogen). Analyzing the size of the ddPCR product, agarose gel electrophoresis (1.5\%) was performed with $4 \mu$ of each sample.

\section{Re-amplification of ddPCR using Q5U polymerase}

If only unsufficient products for 16S rRNA gene sequencing could be extracted from the ddPCR, reamplification was performed. Of note, re-amplification of the ddPCR product is only possible using a non-proofreading polymerase (e.g., Taq polymerase) or by using a polymerase that can read and amplify templates containing uracil (and inosine bases), e.g., Q5U or Phusion U DNA polymerase. The reamplification reaction mix contained: $1 \times \mathrm{Q} 5 \mathrm{U}$ reaction buffer, $200 \mu \mathrm{M}$ dNTPs $(10 \mathrm{mM}) ; 0.5 \mu \mathrm{M}$ P5 primer (forward), $0.5 \mu \mathrm{M} \mathrm{P7}$ primer (reverse), $5 \mu \mathrm{l}$ ddPCR product $(\leq 1 \mathrm{ng} / \mu \mathrm{l}), 0.02 \mathrm{U} / \mu \mathrm{l}$ Q5U Hot Start

Table 4 Cycling conditions for ddPCR using P5 and P7 primer amplifying amplicons

\begin{tabular}{lllll}
\hline Cycling step & $\begin{array}{l}\text { Temperature } \\
\left({ }^{\circ} \mathbf{C}\right)\end{array}$ & Time & Ramp rate & $\begin{array}{l}\text { Number } \\
\text { of cycles }\end{array}$ \\
\hline Enzyme activation & 95 & $5 \mathrm{~min}$ & $2^{\circ} \mathrm{C} / \mathrm{s}$ & 1 \\
Denaturation & 95 & $30 \mathrm{~s}$ & 40 \\
Annealing & 59 & $1 \mathrm{~min}$ & \\
Extension & 72 & $1 \mathrm{~min}$ & \\
Signal stabilization & 4 & $5 \mathrm{~min}$ & 1 \\
& 90 & $5 \mathrm{~min}$ & 1 \\
Hold & 4 & $\infty$ & 1 \\
\hline
\end{tabular}

Table 5 Cycling conditions for re-amplification of ddPCR

\begin{tabular}{llll}
\hline Cycling step & Temperature $\left({ }^{\circ} \mathrm{C}\right)$ & Time & $\begin{array}{l}\text { Number } \\
\text { of cycles }\end{array}$ \\
\hline Initial denaturation & 98 & $30 \mathrm{~s}$ & 1 \\
Denaturation & 95 & $10 \mathrm{~s}$ & 5 \\
Annealing & 55 & $20 \mathrm{~s}$ & \\
Extension & 72 & $45 \mathrm{~s}$ & \\
Final extension & 90 & $5 \mathrm{~min}$ & 1 \\
Hold & 4 & $\infty$ & 1 \\
\hline
\end{tabular}

High-Fidelity DNA Polymerase, up to $50 \mu$ l nucleasefree $\mathrm{H}_{2} \mathrm{O}$. Cycling conditions were set as described in Table 5 .

After the re-amplification, the PCR products were checked for the desired amplicon lengths via agarose gel electrophoresis. Samples showing bands at the desired size were purified by PAGE purification and eluted in $25 \mu \mathrm{l}$ nuclease-free water. Concentrations were measured with the Qubit dsDNA HS Assay using $2 \mu \mathrm{l}$ of the extracted amplicons.

\section{Sequencing}

Samples were adjusted to $0.5 \mathrm{nM}$ and pooled. Samples were sequenced in paired-end modus on a cartridge v3 using PE300 of a MiSeq system (Illumina, Inc.) following the manufacturer's instructions and a final DNA concentration of $12 \mathrm{pM}$ and $15 \%(\mathrm{v} / \mathrm{v})$ PhiX standard library.

\section{Data analysis using IMNGS and Rhea}

Data were processed using the Integrated Microbial Next-Generation Sequencing (IMNGS) pipeline [56], an in-house developed pipeline based on UPARSE [57]. In the advanced IMNGS options, allowed mismatches were set to one. Demultiplexing was performed using a minimum read-length of $250 \mathrm{bp}$ and a maximum read-length of $600 \mathrm{bp}$. Forward trim was set to $30 \mathrm{bp}$ and reverse trim length was $60 \mathrm{bp}$. The abundance filter was set to 0.0025 [58] and the filter of low-read samples was set to 'off'. Chimeric reads were removed using UCHIME [59] and zero-radius operational taxonomic units (zOTUs) were produced using UNOISE 2 [60] and USEARCH v11.0.667. As reference database RDP (project release 11) was used. Refining of taxonomic data was performed using SILVA (release 138). Further analysis was performed in Rhea [61]. Rhea is a collection of R-scripts enabling comparison between samples. After normalization of data, alpha- and betadiversities, richness, and other ecological parameters can be visualized. The script also performs taxonomic binning, enabling an insight on all known and unknown sequences of the microbial composition down to the genus level. 


\section{Abbreviations}

bp: Base pair; ddPCR: Digital droplet PCR; DMSO: Dimethyl sulfoxide; fw: Forward; IMNGS: Integrated Microbial Next-Generation Sequencing pipeline; OTU: Operational taxonomic units; rv: Reverse; $V$ : Variable region of the $16 \mathrm{~S}$ rRNA; v: Version; zOTU: Zero-radius OTU.

\section{Supplementary Information}

The online version contains supplementary material available at https://doi. org/10.1186/s12866-021-02391-z.

Additional file 1 : Supplementary Figure 1. Multi-Dimensional Scaling (MDS) plots show that samples cluster significantly differently due to their origin (human donor and mock community). Moreover, timepoint 1 (e.g.,T30-1 samples) and timepoint 2 samples (e.g.,T30-2) cluster in proximity. (A) Clustering is performed only with samples prepared using $\geq 100 \mathrm{pg}$ DNA input (lower limit for V3-V4). (B) All dilution samples were plotted.

Additional file 2 : Supplementary Table 1. Generalized UniFrac dissimilarity matrix for ZIEL2 samples in comparison to the ideal composition at the genus level. Supplementary Table 2. Phyla-level classification of dilution series for sample T1. In "other" the following phyla are combined: Cyanobacteria, Desulfobacterota, Fusobacteriota, Verrucomicrobiota, and unknown bacteria. Supplementary Table 3. Phyla-level classification of dilution series for sample T30. In "other" the following phyla are combined: Cyanobacteria, Desulfobacterota, Fusobacteriota, Verrucomicrobiota, and unknown bacteria.

\section{Acknowledgments}

We want to thank Angela Sachsenhauser, Lukas Mix, and Caroline Ziegler for excellent technical assistance and Dr. Sandra Reitmeier for her tremendous bioinformatical support. Further, we want to thank Gerassimos Kolaitis, Dr. Josef Sperl, and Prof. Dr. Volker Sieber from the TUM Chair of Chemistry of Biogenic Resources for providing us the ddPCR machine.

\section{Authors' contributions}

I.A-S. conducted the main experiments and supervised A.J.S., who helped developing the protocols. Further, I.A.-S. analyzed the data, wrote the first draft, and prepared figures. K.N. provided resources and was involved in supervision, conceptualization, and conducted final review \& editing. All authors have read and approved the manuscript.

\section{Funding}

I.A-S. was funded by the ZIEL - Institute for Food \& Health with a grant for a doctorate position given to K.N. Open Access funding enabled and organized by Projekt DEAL.

\section{Availability of data and materials}

The datasets generated and analysed during the current study are available in the Sequence Read Archive repository, accession number PRJNA728558. https://www.ncbi.nlm.nih.gov/bioproject/PRJNA728558.

\section{Declarations}

\section{Ethics approval and consent to participate}

Stool samples were obtained from healthy volunteers of age after informed and written consent. An ethics approval is deemed unnecessary according to the statement given in the Drucksache 15/2849 of the German Bundestag about $\S 41$ Abs. 2 Nr. 2S. 1 and 2 Arzneimittelgesetz.

\section{Consent for publication}

Persons providing stool samples are entirely unidentifiable and there are no details on individuals reported within the manuscript. Thus, consent for publication is not applicable.

\section{Competing interests}

KN has ongoing scientific collaborations with HiPP GmbH \& Co. Vertrieb KG (Pfaffenhofen, Germany). All other authors declare that they have no competing interests.
Received: 20 May 2021 Accepted: 15 November 2021

Published: 18 December 2021

\section{References}

1. Lane DJ, Pace B, Olsen GJ, Stahl DA, Sogin ML, Pace NR. Rapid determination of 165 ribosomal RNA sequences for phylogenetic analyses. Proc Natl Acad Sci U S A. 1985;82(20):6955-9.

2. Vos M, Quince C, Pijl AS, de Hollander M, Kowalchuk GA. A comparison of rpoB and $16 \mathrm{~S}$ rRNA as markers in pyrosequencing studies of bacterial diversity. PLoS One. 2012;7(2):e30600.

3. Bukin YS, Galachyants YP, Morozov IV, Bukin SV, Zakharenko AS, Zemskaya TI. The effect of $16 \mathrm{~S}$ rRNA region choice on bacterial community metabarcoding results. Sci Data. 2019;6(1):190007.

4. Flores R, Shi J, Yu G, Ma B, Ravel J, Goedert JJ, et al. Collection media and delayed freezing effects on microbial composition of human stool. Microbiome. 2015:3:33.

5. Choo JM, Leong LE, Rogers GB. Sample storage conditions significantly influence faecal microbiome profiles. Sci Rep. 2015;5:16350.

6. Ma J, Sheng L, Hong Y, Xi C, Gu Y, Zheng N, et al. Variations of gut microbiome profile under different storage conditions and preservation periods: a multi-dimensional evaluation. Front Microbiol. 2020;11:972.

7. Penington JS, Penno MAS, Ngui KM, Ajami NJ, Roth-Schulze AJ, Wilcox SA, et al. Influence of fecal collection conditions and 165 rRNA gene sequencing at two centers on human gut microbiota analysis. Sci Rep. 2018;8(1):4386

8. Abellan-Schneyder I, Matchado MS, Reitmeier S, Sommer A, Sewald Z, Baumbach J, et al. Primer, pipelines, parameters: issues in 16S rRNA gene sequencing. mSphere. 2021;6(1):e01202-20.

9. Fouhy F, Clooney AG, Stanton C, Claesson MJ, Cotter PD. 16S rRNA gene sequencing of mock microbial populations- impact of DNA extraction method, primer choice and sequencing platform. BMC Microbiol. 2016;16(1):123.

10. Klindworth A, Pruesse E, Schweer T, Peplies J, Quast C, Horn M, et al. Evaluation of general 165 ribosomal RNA gene PCR primers for classical and next-generation sequencing-based diversity studies. Nucleic Acids Res. 2012;41(1):e1.

11. Thijs S, Op De Beeck M, Beckers B, Truyens S, Stevens V, Van Hamme JD, et al. Comparative evaluation of four bacteria-specific primer pairs for $16 \mathrm{~S}$ rRNA gene surveys. Front Microbiol. 2017:8:494.

12. Tremblay J, Singh K, Fern A, Kirton ES, He S, Woyke T, et al. Primer and platform effects on 165 rRNA tag sequencing. Front Microbiol. 2015;6:771.

13. Almeida A, Mitchell AL, Tarkowska A, Finn RD. Benchmarking taxonomic assignments based on $16 \mathrm{~S}$ rRNA gene profiling of the microbiota from commonly sampled environments. GigaScience. 2018;7(5):giy054.

14. De Filippis F, Parente E, Zotta T, Ercolini D. A comparison of bioinformatic approaches for $16 \mathrm{~S}$ rRNA gene profiling of food bacterial microbiota. Int J Food Microbiol. 2018:265:9-17.

15. Marizzoni M, Gurry T, Provasi S, Greub G, Lopizzo N, Ribaldi F, et al. Comparison of bioinformatics pipelines and operating Systems for the Analyses of $16 \mathrm{~S}$ rRNA gene amplicon sequences in human fecal samples. Front Microbiol. 2020;11:1262.

16. Park S-C, Won S. Evaluation of 16 S rRNA databases for taxonomic assignments using mock community. Genomics Inform. 2018;16(4):e24.

17. Sierra MA, Li Q, Pushalkar S, Paul B, Sandoval TA, Kamer AR, et al. The influences of bioinformatics tools and reference databases in analyzing the human oral microbial community. Genes (Basel). 2020;11(8):878.

18. Nearing JT, Douglas GM, Comeau AM, Langille MGI. Denoising the Denoisers: an independent evaluation of microbiome sequence errorcorrection approaches. PeerJ. 2018;6:e5364.

19. Fiedorová K, Radvanský M, Němcová E, Grombiř́ková H, Bosák J, Černochová $M$, et al. The impact of DNA extraction methods on stool bacterial and fungal microbiota community recovery. Front Microbiol. 2019;10:821.

20. Wesolowska-Andersen A, Bahl MI, Carvalho V, Kristiansen K, SicheritzPontén T, Gupta R, et al. Choice of bacterial DNA extraction method from fecal material influences community structure as evaluated by metagenomic analysis. Microbiome. 2014;2(1):19. 
21. Hart ML, Meyer A, Johnson PJ, Ericsson AC. Comparative evaluation of DNA extraction methods from feces of multiple host species for downstream next-generation sequencing. PLoS One. 2015;10(11):e0143334.

22. Lim MY, Song E-J, Kim SH, Lee J, Nam Y-D. Comparison of DNA extraction methods for human gut microbial community profiling. Syst Appl Microbiol. 2018;41(2):151-7.

23. Wagner Mackenzie B, Waite DW, Taylor MW. Evaluating variation in human gut microbiota profiles due to DNA extraction method and intersubject differences. Front Microbiol. 2015;6:130.

24. Santiago A, Panda S, Mengels G, Martinez X, Azpiroz F, Dore J, et al. Processing faecal samples: a step forward for standards in microbial community analysis. BMC Microbiol. 2014;14(1):112.

25. Costea PI, Zeller G, Sunagawa S, Pelletier E, Alberti A, Levenez F, et al. Towards standards for human fecal sample processing in metagenomic studies. Nat Biotechnol. 2017;35(11):1069-76.

26. McOrist AL, Jackson M, Bird AR. A comparison of five methods for extraction of bacterial DNA from human faecal samples. J Microbiol Methods. 2002;50(2):131-9.

27. Multinu F, Harrington SC, Chen J, Jeraldo PR, Johnson S, Chia N, et al. Systematic Bias introduced by genomic DNA template dilution in $16 \mathrm{~S}$ rRNA gene-targeted microbiota profiling in human stool homogenates. mSphere. 2018;3(2):e00560-17.

28. Salter SJ, Cox MJ, Turek EM, Calus ST, Cookson WO, Moffatt MF, et al. Reagent and laboratory contamination can critically impact sequence-based microbiome analyses. BMC Biol. 2014;12(1):87.

29. Glassing A, Dowd SE, Galandiuk S, Davis B, Chiodini RJ. Inherent bacterial DNA contamination of extraction and sequencing reagents may affect interpretation of microbiota in low bacterial biomass samples. Gut Pathogens. 2016;8(1):24.

30. Dahlberg J, Sun L, Persson Waller K, Östensson K, McGuire M, Agenäs $\mathrm{S}$, et al. Microbiota data from low biomass milk samples is markedly affected by laboratory and reagent contamination. PLoS One. 2019;14(6):e0218257.

31. Claassen-Weitz S, Gardner-Lubbe S, Mwaikono KS, du Toit E, Zar HJ, Nicol MP. Optimizing 16S rRNA gene profile analysis from low biomass nasopharyngeal and induced sputum specimens. BMC Microbiol. 2020;20(1):113.

32. Saladié M, Caparrós-Martín JA, Agudelo-Romero P, Wark PAB, Stick SM, O'Gara F. Microbiomic analysis on low abundant respiratory biomass samples; improved recovery of microbial DNA from bronchoalveolar lavage fluid. Front Microbiol. 2020;11:2477.

33. Stinson LF, Keelan JA, Payne MS. Identification and removal of contaminating microbial DNA from PCR reagents: impact on low-biomass microbiome analyses. Lett Appl Microbiol. 2019;68(1):2-8.

34. Davis A, Kohler C, Alsallaq R, Hayden R, Maron G, Margolis E. Improved yield and accuracy for DNA extraction in microbiome studies with variation in microbial biomass. BioTechniques. 2019;66(6):285-9.

35. Douglas CA, Ivey KL, Papanicolas LE, Best KP, Muhlhausler BS, Rogers GB. DNA extraction approaches substantially influence the assessment of the human breast milk microbiome. Sci Rep. 2020;10(1):123.

36. Brandt J, Albertsen M. Investigation of detection limits and the influence of DNA extraction and primer choice on the observed microbial communities in drinking water samples using 165 rRNA gene amplicon sequencing. Front Microbiol. 2018:9:2140.

37. Velásquez-Mejía EP, de la Cuesta-Zuluaga J, Escobar JS. Impact of DNA extraction, sample dilution, and reagent contamination on 165 rRNA gene sequencing of human feces. Appl Microbiol Biotechnol. 2018;102(1):403-11.

38. Reitmeier S, Kiessling S, Neuhaus K, Haller D. Comparing circadian rhythmicity in the human gut microbiome. STAR Protoc. 2020;1(3):100148.

39. Dreo T, Pirc M, Ramsak Z, Pavsic J, Milavec M, Zel J, et al. Optimising droplet digital PCR analysis approaches for detection and quantification of bacteria: a case study of fire blight and potato brown rot. Anal Bioanal Chem. 2014;406(26):6513-28.

40. Hindson BJ, Ness KD, Masquelier DA, Belgrader P, Heredia NJ, Makarewicz AJ, et al. High-throughput droplet digital PCR system for absolute quantitation of DNA copy number. Anal Chem. 2011;83(22):8604-10.

41. Demeke T, Dobnik D. Critical assessment of digital PCR for the detection and quantification of genetically modified organisms. Anal Bioanal Chem. 2018;410(17):4039-50.
42. Gobert G, Cotillard A, Fourmestraux C, Pruvost L, Miguet J, Boyer M. Droplet digital PCR improves absolute quantification of viable lactic acid bacteria in faecal samples. J Microbiol Methods. 2018;148:64-73.

43. Wouters Y, Dalloyaux D, Christenhusz A, Roelofs HMJ, Wertheim HF, Bleeker-Rovers CP, et al. Droplet digital polymerase chain reaction for rapid broad-spectrum detection of bloodstream infections. Microb Biotechnol. 2020;13(3):657-68.

44. Boers SA, Hays JP, Jansen R. Micelle PCR reduces chimera formation in 165 rRNA profiling of complex microbial DNA mixtures. Sci Rep. 2015;5:14181.

45. Valencia CA, Rhodenizer D, Bhide S, Chin E, Littlejohn MR, Keong LM, et al. Assessment of target enrichment platforms using massively parallel sequencing for the mutation detection for congenital muscular dystrophy. J Mol Diagn. 2012;14(3):233-46.

46. Komori HK, LaMere SA, Torkamani A, Hart GT, Kotsopoulos S, Warner J, et al. Application of microdroplet PCR for large-scale targeted bisulfite sequencing. Genome Res. 2011;21(10):1738-45.

47. Philippe J, Derhourhi M, Durand E, Vaillant E, Dechaume A, Rabearivelo I, et al. What is the best NGS enrichment method for the molecular diagnosis of monogenic diabetes and obesity? PLoS One. 2015;10(11):e0143373.

48. Pruvost M, Grange T, Geigl E-M. Minimizing DNA contamination by using UNG-coupled quantitative real-time PCR on degraded DNA samples: application to ancient DNA studies. BioTech. 2005;38(4):569-75.

49. Kasalický V, Jezbera J, Hahn MW, Šimek K. The diversity of the Limnohabitans genus, an important group of freshwater bacterioplankton, by characterization of 35 isolated strains. PLoS One. 2013;8(3):e58209.

50. Nelson MC, Morrison HG, Benjamino J, Grim SL, Graf J. Analysis, optimization and verification of Illumina-generated 16S rRNA gene amplicon surveys. PLoS One. 2014;9(4):e94249.

51. Manzari C, Oranger A, Fosso B, Piancone E, Pesole G, D'Erchia AM. Accurate quantification of bacterial abundance in metagenomic DNAs accounting for variable DNA integrity levels. Microb Genomics. 2020;6(10). https://doi.org/10.1099/mgen.0.000417.

52. Pacocha N, Scheler O, Nowak MM, Derzsi L, Cichy J, Garstecki P. Direct droplet digital PCR (dddPCR) for species specific, accurate and precise quantification of bacteria in mixed samples. Anal Methods. 2019;11(44):5730-5.

53. Ziegler I, Lindström S, Källgren M, Strålin K, Mölling P. 16S rDNA droplet digital PCR for monitoring bacterial DNAemia in bloodstream infections. PLoS One. 2019;14(11):e0224656.

54. Godon JJ, Zumstein E, Dabert P, Habouzit F, Moletta R. Molecular microbial diversity of an anaerobic digestor as determined by small-subunit rDNA sequence analysis. Appl Environ Microbiol. 1997;63(7):2802-13.

55. Foote AD, Thomsen PF, Sveegaard S, Wahlberg M, Kielgast J, Kyhn LA, et al. Investigating the potential use of environmental DNA (eDNA) for genetic monitoring of marine mammals. PLoS One. 2012;7(8):e41781.

56. Lagkouvardos I, Joseph D, Kapfhammer M, Giritli S, Horn M, Haller D, et al. IMNGS: a comprehensive open resource of processed 16S rRNA microbial profiles for ecology and diversity studies. Sci Rep. 2016;6:33721.

57. Edgar RC. UPARSE: highly accurate OTU sequences from microbial amplicon reads. Nat Methods. 2013;10(10):996-8.

58. Reitmeier S, Hitch TCA, Treichel N, et al. Handling of spurious sequences affects the outcome of highthroughput16S rRNA gene amplicon profiling. ISME Commun. 2021;1(1):1-12.

59. Edgar RC, Haas BJ, Clemente JC, Quince C, Knight R. UCHIME improves sensitivity and speed of chimera detection. Bioinformatics. 2011;27(16):2194-200.

60. Edgar RC. UNOISE2: improved error-correction for Illumina 165 and ITS amplicon sequencing. BioRxiv. 2016:081257.

61. Lagkouvardos I, Fischer S, Kumar N, Clavel T. Rhea: a transparent and modular R pipeline for microbial profiling based on 165 rRNA gene amplicons. PeerJ. 2017;5:e2836.

62. Turner S, Pryer KM, Miao VP, Palmer JD. Investigating deep phylogenetic relationships among cyanobacteria and plastids by small subunit rRNA sequence analysis. J Eukaryot Microbiol. 1999;46(4):327-38.

\section{Publisher's Note}

Springer Nature remains neutral with regard to jurisdictional claims in published maps and institutional affiliations. 